\title{
Blood markers of endothelial dysfunction and their correlation to cerebrovascular reactivity in patients with chronic hepatitis C infection
}

\author{
Mirela Pavicic Ivelja ${ }^{\text {Corresp., } 1}$, Kresimir Dolic ${ }^{2}$, Leida Tandara ${ }^{3}$, Nikola Perkovic ${ }^{4}$, Antonio Mestrovic ${ }^{4}$, Ivo Ivic \\ ${ }^{1}$ University of Split School of Medicine, University Hospital of Split, Department of infectious diseases, Split, Croatia, Croatia \\ 2 University of Split School of Medicine, University Hospital of Split, Department of radiology, Split, Croatia, Croatia \\ 3 University of Split School of Medicine, University Hospital of Split, Department of medical laboratory diagnostic, Split, Croatia, Croatia \\ ${ }^{4}$ University of Split School of Medicine, University Hospital of Split, Department of gastroenterology, Split, Croatia, Croatia \\ Corresponding Author: Mirela Pavicic Ivelja \\ Email address: mpavivelj@kbsplit.hr
}

Although liver cirrhosis and hepatocellular carcinoma are major consequences of hepatitis $\mathrm{C}(\mathrm{HCV})$, there has been an increasing number of studies examining extrahepatic manifestations, especially those caused by systemic chronic inflammation and metabolic complications that might predispose HCV patients to atherosclerosis and ischemic cerebrovascular disease (CVD). The aim of our study was to assess E-selectin, VCAM-1, ICAM-1 and VEGF-A serum levels in patients with chronic HCV infection and to correlate them with cerebrovascular reactivity. A blood sample was taken from eighteen patients with chronic hepatitis $\mathrm{C}$ infection and from the same number of healthy blood donors in the control group. The aim was to analyse markers of endothelial dysfunction and to correlate them with cerebrovascular reactivity expressed as breath-holding index (BHI) determined using transcranial color Doppler. The obtained results revealed significant differences between the groups in all endothelial markers except for the E selectin. While the ICAM-1 and SVCAM-1 were significantly increased in the hepatitis group, VEGF-A was significantly decreased. A significant reduction of $0.5(95 \% \mathrm{Cl} 0.2,0.8)$ in the mean $\mathrm{BHI}$ was found in the hepatitis group (mean BHI 0.64) compared to controls (mean BHI 1.10). No significant association between the $\mathrm{BHI}$ and any of the endothelial markers was found in the control group, while in the hepatitis group, the scatter plot of ICAM-1 vs BHI suggested that the association might be present. In conclusion, the results of this study confirm an association between a chronic HCV infection and altered cerebrovascular reactivity as well as higher levels of markers of endothelial activation (ICAM-1, VCAM-1) as possible indicators of an increased CVD risk. 


\section{Blood markers of endothelial dysfunction and their}

2 correlation to cerebrovascular reactivity in patients with

3 chronic hepatitis $\mathrm{C}$ infection

4

5 Mirela Pavicic Ivelja ${ }^{1}$, Kresimir Dolic ${ }^{2}$, Leida Tandara ${ }^{3}$, Nikola Perkovic ${ }^{4}$, Antonio Mestrovic ${ }^{4}$, Ivo

6 Ivic $^{1}$

$8{ }^{1}$ Department of Infectious Diseases, University Hospital of Split, University of Split School of

9 Medicine, Split, Croatia

${ }^{2}$ Department of Radiology, University Hospital of Split, University of Split School of Medicine,

Split, Croatia

${ }^{3}$ Department of Medical laboratory diagnostic, University Hospital of Split, University of Split

School of Medicine, Split, Croatia

${ }^{4}$ Department of Gastroenterology, University Hospital of Split, University of Split School of

Medicine, Split, Croatia

\section{Corresponding author}

Mirela Pavicic Ivelja ${ }^{1}$ 
e-mail: mmarendic@gmail.com

20

\section{Abstract}

Although liver cirrhosis and hepatocellular carcinoma are major consequences of hepatitis $C$ (HCV), there has been an increasing number of studies examining extrahepatic manifestations, especially those caused by systemic chronic inflammation and metabolic complications that might predispose HCV patients to atherosclerosis and ischemic cerebrovascular disease (CVD). The aim of our study was to assess E-selectin, VCAM-1, ICAM-1 and VEGF-A serum levels in patients with chronic $\mathrm{HCV}$ infection and to correlate them with cerebrovascular reactivity. A blood sample was taken from eighteen patients with chronic hepatitis $\mathrm{C}$ infection and from the same number of healthy blood donors in the control group. The aim was to analyse markers of endothelial dysfunction and to correlate them with cerebrovascular reactivity expressed as breath-holding index (BHI) determined using transcranial color Doppler. The obtained results revealed significant differences between the groups in all endothelial markers except for the $E$ selectin. While the ICAM-1 and SVCAM-1 were significantly increased in the hepatitis group, VEGF-A was significantly decreased. A significant reduction of $0.5(95 \% \mathrm{Cl} 0.2,0.8)$ in the mean $\mathrm{BHI}$ was found in the hepatitis group (mean $\mathrm{BHI} 0.64$ ) compared to controls (mean $\mathrm{BHI} 1.10$ ). No significant association between the $\mathrm{BHI}$ and any of the endothelial markers was found in the control group, while in the hepatitis group, the scatter plot of ICAM-1 vs BHI suggested that the association might be present. In conclusion, the results of this study confirm an association between a chronic HCV infection and altered cerebrovascular reactivity as well as higher levels 
39 of markers of endothelial activation (ICAM-1, VCAM-1) as possible indicators of an increased

40 CVD risk.

\section{Introduction}

42 Despite the availability of well-tolerated and effective treatments with novel oral antivirals

43 (direct-acting antivirals, DAA) over the last few years, hepatitis C (HCV) still remains a major

44 global health problem. It is estimated that 71 million people worldwide are chronically infected

45 with HCV, 14 million of which in the European Region (Steffen et al., 2020; Petruzziello et al.,

46 2016). The major burden of the chronic HCV infection comes from liver cirrhosis, hepatocellular

47 carcinoma and liver transplantation. However, extrahepatic manifestations of chronic hepatitis

48 C are increasingly being studied. Some of them are immune mediated and others are driven by

49 systemic chronic inflammation and metabolic complications that might predispose patients to

50 atherosclerosis, including cerebrovascular atherosclerosis (Cacoub et al., 2016).

51 Cerebrovascular disease (CVD) is a major health challenge with an increasing number of CVD-

52 related deaths and disabilities. Conventional risk factors for CVD include ageing, smoking,

53 alcohol consumption, obesity, hyperlipidemia, hypertension, atrial fibrillation and diabetes. In

54 addition to the aforementioned, new risk factors such as infectious agents and inflammation,

55 have been documented (Feigin et al., 2014; Hu et al., 2017; Boehme, Esenwa, Elkind 2017).

56 Although numerous studies have linked HCV to a higher prevalence of CVD, this relationship, as

57 well as the assumed pathophysiological mechanism, still remain controversial. HCV is generally

58 thought to stimulate pro-inflammatory cytokine synthesis leading to pro-atherogenic activity

59 (Lee et al., 20101; Liao et al., 2012; Huang, Kang, Zhao, 2014; Ambrosino et al., 2016;).

Peer] reviewing PDF | (2020:09:52991:1:1:NEW 12 Dec 2020) 
60

61

62

Consequently, E -selectin, intracellular adhesion molecule-1 (ICAM-1), vascular cellular adhesion molecule-1 (VCAM-1) as markers of endothelial activation, as well as vascular endothelial growth factor -A (VEGF-A) as the regulator of angiogenesis, have been found to be potential indicators of endothelial dysfunction, atherosclerosis and risk of CVD (Stanimirovic et al., 1997; Blann et al., 1999; Poggesi et al., 2016; Billinger et al., 2017; Tchalla et al., 2017; Setyopranoto et al., 2019; Varona et al., 2019).

Ultrasound data were collected as previously described in Ivelja et al., (2019) using transcranial color Doppler sonography (TCCD) which allows a rapid and non-invasive investigation of cerebral blood flow (CBF) velocities in the large cerebral arteries and velocity changes after a vasodilatory stimulus such as apnea. These changes, known as cerebrovascular reactivity, are considered an indicator of the capability of adaptive changes in CBF and can be reduced in patients under risk of CVD (Markus, Harrison, 1992; Silvestrini et al., 1996; Apruzzese et al., 2001).

Since in previous studies HCV was found to be associated with higher prevalence of stroke, the aim of our study was to assess E-selectin, VCAM-1, ICAM-1, VEGF-A serum levels in patients with chronic HCV infection and to correlate them with cerebrovascular reactivity assessed by breath-holding technique.

\section{Materials and methods}

An cross-sectional observational study was performed at the University Hospital of Split, Croatia after being granted by the University Hospital of Split Ethics Committee (Reg. No.: 2181-147-01/06/J.B.-14-2).Written informed consent was obtained from all participants. Two 
81 groups of participants were investigated: group one included 18 chronic hepatitis C patients

82 and group two consisted of 18 healthy blood donor volunteers whose blood is regulary tested

83 for blood-borne diseases including HCV. Patient's medical history included past and current

84 diseases, laboratory tests, including blood sugar and lipid profile done within three months

85

86

87

88

89

90

91

92

93

94

95

96

97

98

99

100

101

102

prior study entrance, and information on alcohol consumption and smoking. Exclusion criteria

were: history of hypertension, diabetes mellitus, CVD, hematologic disease, cirrhosis, chronic

heart disease, malignancy, excessive alcohol consumption defined as more than 7 drinks per

week for women and more than 14 drinks per week for men, as well as therapy with $\beta$-blocking

agents, hormonal substances, nitrates, calcium channel blockers, vasodilatory drugs and

anticoagulants (Rimm et al., 1996; Mukamal et al., 2010; Stoutenberg et al., 2013). Because of

inadequate insonation of their middle cerebral artery (MCA), two participants, one from each

group, were excluded from the study. The groups were balanced by age, BMI, sex, and alcohol

intake (Table 1). In the hepatitis group the estimated mean \pm SD duration of disease was $14.6 \pm$

5.5 years. However, the only significant difference between the control and the hepatitis group

was the prevalence of smoking with the odds of smoking in hepatitis group being $~ 9$ higher

than in controls (OR 9.1, 95\% Cl 1.64-55.10). Table 1

Venous blood samples were collected from all participants included in the study. Blood was collected in serum tubes and then centrifuged. Serum aliquots for determination of E-selectin,

ICAM-1, VCAM-1 and VEGF-A were stored at $-20^{\circ} \mathrm{C}$ until analysis. Biochemical analyses were performed using the enzyme-linked immunosorbent ELISA assay (eBioscience, Vienna, Austria).

All subjects underwent TCCD assessment using the Acuson X500 Ultrasound system (Siemens, Erlangen, Germany) with a P4-2 (2-4 MHz frequency) transducer during afternoon in a quiet 
103 room while lying in a comfortable supine position after 5 minutes of bedrest. After measuring

104 their blood pressure, the dominant side circle of Willis arteries was insonated, which means

105 exposed to ultrasound waves, through the temporal bone window with the special focus on

106 the MCA. Cerebrovascular reactivity to hypercapnia was evaluated by means of well-

107 established breath-holding test with MCA blood flow mean velocity (Vmean) first measured at

108 rest and then continuously during the test (Markus, Harrison 1992; Silvestrini et al., 1996;

109 Settakis et al., 2002; Rodriguez-Flores et al., 2014). Participants were asked to hold their breath

110 following normal inspiration for as long as they could. MCV Vmean and duration of breath-hold

111 measured in seconds were recorded. The whole procedure was repeated after 3 to 4 minutes of

112 rest. Mean values of each variable from both measurements were determined and then taken

113 into calculations for breath-holding index $(\mathrm{BHI})$, a ratio between the percentage of increase of

114 Vmean during breath-holding and the duration of breath-holding.

115 Statistical analysis

116 Statistical analysis was performed using the SPSS package (version 24.0; Chicago, Illinois). Fisher

117 exact test was used to test the difference in distribution of qualitative data between the

118 hepatitis and control group. For quantitative data, depending on the data distribution, either

119 Mann-Whitney $\mathrm{U}$ tests or t-test for independent samples were used. Multiple linear regression

120 models of a endothelial marker level with both hepatitis group and smoking status as

121 independent variables were used to corroborate if the observed difference in a endothelial

122 marker level between the groups is independent of a smoking status. To investigate correlation

123 between the $\mathrm{BHI}$ and endothelial markers we calculated Pearson's correlation coefficients. The

124 significance level was set at 0.05 .

Peer] reviewing PDF | (2020:09:52991:1:1:NEW 12 Dec 2020) 
125 Results

126 Markers of endothelial dysfunction as well as $\mathrm{BHI}$ in hepatitis $\mathrm{C}$ patients and controls are

127 presented in Table 2. There were significant differences between the groups in all the

128 endothelial markers except for E selectin. While the ICAM-1 and sVCAM-1 significantly

129 increased in the hepatitis group, VEGF-A significantly decreased. Table 2.Observed differences

130 in endothelial marker level remained significant even after adjusting for smoking (regression

131 models; P<0.020 for ICAM-1, sVCAM-1 and VEGF-A). Table3.

132 A significant reduction of $0.5(95 \% \mathrm{Cl} 0.2,0.8)$ in the mean $\mathrm{BHI}$ was found in the hepatitis group

133 (mean $\mathrm{BHI} 0.64$ ) compared to controls (mean BHI 1.10). (Table 2). No significant association of

$134 \mathrm{BHI}$ with any of endothelial markers was identified in the both groups studied . Table 4

135 However in the hepatitis group the scatter plot of ICAM-1 vs BHI suggests that the association

136 might be present (Fig 1). Nevertheless, due to the small sample size, the pattern on the scatter

137 plot is not clear and the association might reflect a false positive finding. Fig 1.

138 Discussion

139 Our study showed that cerebrovascular reactivity values, calculated as the BHI, were

140 significantly lower in the HCV group than in the healthy control group. Similar results were

141 obtained in our previous study which consisted only of ultrasound parameters, emphasising

142 reduction of vasodilatatory capacity of the cerebral arteries in patients with chronic hepatitis C

143 (Pavicic Ivelja et al., 2019). The above mentioned findings suggest an unfavorable effect of 
144 chronic HCV infection on cerebrovascular hemodynamics and might lead to an increased risk of

145 CVD. However, the pathogenesis of the assumed HCV and CVD connection, although probably

146 involving atherosclerosis, is still mostly undefined (Rosenfeld, Campbell, 2011; Masiá et al.,

147 2011). Chronic infections are assumed to stimulate a prolonged systemic inflammatory

148 response leading to blood vessel endothelium damaging and eventually to atherosclerosis

149 development (Campbell, Rosenfeld, 2015). Therefore, markers of endothelial activation (E-

150 selectin, ICAM-1, VCAM-1) and the regulator of angiogenesis VEGF-A were included in our

151 research. The obtained results show that hepatitis C group had significantly higher

152 concentrations of ICAM-1 and SVCAM-1 compared to controls which is in accordance with most

153 results of previous studies dealing with $\mathrm{HCV}$, endothelial dysfunction and higher risk of CVD

154 (Stanimirovic et al., 1997; Blann et al., 1999; Martinic-Popovic et al., 2014). Authors of some

155 recent studies went a step further alleging that the new DAA treatment reverses these chronic

156 HCV effects and enhances endothelial function (Schmidt et al., 2018; Davis JS et al., 2018;

157 Muñoz-Hernández R et al., 2020). In our research, HCV patients had decreased VEGF-A

158 compared to healthy controls opposing several earlier studies connecting higher levels of VEGF-

159 A with the risk of ischemic CVD (Shoamanesh et al., 2016). Salum et al. in their study showed

160 that patients with chronic HCV infection and late fibrotic stages of liver disease had the highest

161 levels of VEGF-A compared to healthy controls (Salum et al., 2017). Since the advanced stage of

162 liver fibrosis, regardless of its etiology, is characterized by hemodynamic alterations, cirrhotic

163 patients were not included in our study. This is likely the reason why we had contrasting results

164 connected with VEGF-A but it could also imply that the concentration of this biomarker may not

165 be relevant if HCV is taken as an independent risk factor for CVD and that it has more to do with 
166 the progression of liver fibrosis. Same interpretation could be given for our E-selectin results

167 (no significant differences between the groups, Table 2) since previous research also suggested

168 its association mostly with severity of liver fibrosis (Kaplanski et al., 2017; Montalto et al.,

169 2001). Although we got significant independent results for ultrasound parameters of

170 cerebrovascular reactivity as well as blood markers of endothelial dysfunction, we wanted to

171 combine these two methods as this has not been previously done in the context of chronic

172 hepatitis $\mathrm{C}$ and risk of CVD. No significant association of $\mathrm{BHI}$ with any of endothelial markers

173 was identified in the control group. However, in the hepatitis group, BHI was moderately

174 associated with ICAM-1 at the 0.1 significance level (Table 4) indicating the need for further

175 studies with a larger number of participants including post-DAA HCV patients. Also, the fact that

176 cirrhotic patients were not included, and still such significant differences in cerebrovascular

177 reactivity and markers of endothelial dysfunction are present, implies the need for active

178 diagnosis and early treatment of HCV patients, especially nowadays with available effective

179 DAA treatment. Thus, not only the progression of liver damage but also possible systemic

180 atherosclerosis induced by chronic inflammation could be prevented. The focus of our work

181 was on cerebral vasoreactivity which probably reflects systemic impairment of the vascular

182 system rather than isolated cerebrovascular dysfunction. In that sense it would be interesting in

183 future research to evaluate established methods in assessing peripheral vascular endothelial

184 function like brachial artery flow-mediated dilation (FMD) and reactive hyperemia-peripheral

185 arterial tonometry (RH-PAT) in HCV patients. (Staszewski J et al., 2019)

186 The main limitation of the study is a small sample size which allowed only for inclusion of

187 limited number of predictors in multiple linear regression (HCV status and smoking Yes/No), 
188 and thus hindered investigation of possible effects of confounding variables. A much larger

189 sample size and multiple regression model with more factors would be required in future

190 studies to mitigate this effect. Although we excluded examinees with clinical, laboratory and

191 ultrasound features of cirrhosis from the study we did not preform fibrosis score which could

192 also be considered as a study limitation.

193 In conclusion, $\mathrm{BHI}$ findings in our study suggest that patients with chronic hepatitis $\mathrm{C}$ have an

194 altered cerebrovascular reactivity and a higher risk of unfavourable cerebrovascular events.

195 Additional evidence has also been provided to link the above-mentioned markers of endothelial

196 dysfunction and CVD risk in patients with chronic HCV infection. The question remains whether

197 the level of these markers, or at least one of them, combined with BHI could potentially be used

198 in assessing the risk of CVD in patients with chronic hepatitis C. If proven to be useful after

199 additional studies, endothelial markers together with $\mathrm{BHI}$ could be of great assistance in the

200 comprehensive evaluation of HCV patients and CVD prevention.

201 Acknowlegments

202 None to state.

203 References

1. Steffen G, Sperle I, Leendertz SA, Sarma N, Beermann S, Thamm R, Bremer V,

Zimmermann R, Dudareva S. The epidemiology of Hepatitis B, C and D in Germany: A 
scoping review. PLoS One. 2020;15(3):e0229166. Published 2020 Mar 9.

207

doi:10.1371/journal.pone.0229166

2. Petruzziello A, Marigliano S, Loquercio G, Cozzolino A, Cacciapuoti C. Global epidemiology of hepatitis C virus infection: An up-date of the distribution and circulation of hepatitis C virus genotypes. World J Gastroenterol. 2016;22(34):7824-7840. doi:10.3748/wjg.v22.i34.7824

3. Cacoub P, Comarmond C, Domont F, Savey L, Desbois AC, Saadoun D. Extrahepatic manifestations of chronic hepatitis C virus infection. Ther Adv Infect Dis. 2016;3(1):3-14. doi:10.1177/2049936115585942

4. Hu X, De Silva TM, Chen J, Faraci FM. Cerebral Vascular Disease and Neurovascular Injury in Ischemic Stroke. Circ Res. 2017;120(3):449-471. doi:10.1161/CIRCRESAHA.116.308427

5. Krishnamurthi RV, Feigin VL, Forouzanfar MH, Mensah GA, Connor M, Bennett DA, Moran AE, Sacco RL, Anderson LM, Truelsen T, O'Donnell M, Venketasubramanian N, Barker-Collo S, Lawes CM, Wang W, Shinohara Y, Witt E, Ezzati M, Naghavi M, Murray C; Global Burden of Diseases, Injuries, Risk Factors Study 2010 (GBD 2010); GBD Stroke Experts Group. Global and regional burden of first-ever ischaemic and haemorrhagic stroke during 1990-2010: findings from the Global Burden of Disease Study 2010. Lancet Glob Health. 2013 Nov;1(5):e259-81. doi: 10.1016/S2214-109X(13)70089-5. Epub 2013 Oct 24. PMID: 25104492; PMCID: PMC4181351.

6. Boehme AK, Esenwa C, Elkind MS. Stroke Risk Factors, Genetics, and Prevention. Circ Res. 2017;120(3):472-495. doi:10.1161/CIRCRESAHA.116.308398 
7. Ambrosino P, Lupoli R, Di Minno A, Tarantino L, Spadarella G, Tarantino P, Nasto A, Celentano A, Di Minno MN. . The risk of coronary artery disease and cerebrovascular disease in patients with hepatitis C: A systematic review and meta-analysis. Int J Cardiol. 2016 Oct 15;221:746-54. doi: 10.1016/j.ijcard.2016.06.337. Epub 2016 Jul 4. Increase Risk for Stroke? A Population-Based Cohort Study. PLoS ONE 7(2): e31527. https://doi.org/10.1371/journal.pone.0031527

9. Lee $\mathrm{MH}$, Yang $\mathrm{HI}$, Wang $\mathrm{CH}$, Jen $\mathrm{CL}$, Yeh SH, Liu CJ, You SL, Chen WJ, Chen CJ. Hepatitis C 2900. virus infection and increased risk of cerebrovascular disease. Stroke 2010;41: 2894 -

10. Huang $H$, Kang R, Zhao Z. Is hepatitis $C$ associated with atherosclerotic burden? A systematic review and meta-analysis. PLoS One. 2014;9(9):e106376. Published 2014 Sep 3. doi:10.1371/journal.pone.0106376

11. Setyopranoto I, Sadewa AH, Wibowo S, Widyadharma IPE. Comparison of Mean VEGF-A Expression Between Acute Ischemic Stroke Patients and Non-Ischemic Stroke Subjects. Open Access Maced J Med Sci. 2019;7(5):747-751. Published 2019 Mar 13. doi:10.3889/oamjms.2019.175

12. Billinger SA, Sisante JV, Mattlage AE, Alqahtani AS, Abraham MG, Rymer MM, Camarata PJ. The relationship of pro-inflammatory markers to vascular endothelial function after acute stroke. Int J Neurosci. 2017;127(6):486-492.

doi:10.1080/00207454.2016.1198344 
13. Poggesi A, Pasi M, Pescini F, Pantoni L, Inzitari D. Circulating biologic markers of endothelial dysfunction in cerebral small vessel disease: A review. J Cereb Blood Flow Metab. 2016;36(1):72-94. doi:10.1038/jcbfm.2015.116

14. Blann A, Kumar P, Krupinski J, McCollum C, Beevers DG, Lip GY. Soluble intercelluar adhesion molecule-1, E-selectin, vascular cell adhesion molecule-1 and von Willebrand factor in stroke. Blood Coagul Fibrinolysis. 1999 Jul;10(5):277-84.

15. Stanimirovic DB, Wong J, Shapiro A, Durkin JP. Increase in surface expression of ICAM-1, VCAM-1 and E-selectin in human cerebromicrovascular endothelial cells subjected to ischemia-like insults. Acta Neurochir Suppl. 1997;70:12-16. doi:10.1007/978-3-70916837-0_4

16. Tchalla AE, Wellenius GA, Sorond FA, Gagnon M, Iloputaife I, Travison TG, Dantoine T, Lipsitz LA. Elevated Soluble Vascular Cell Adhesion Molecule-1 Is Associated With Cerebrovascular Resistance and Cognitive Function. J Gerontol A Biol Sci Med Sci. 2017;72(4):560-566. doi:10.1093/gerona/glw099

17. Varona JF, Ortiz-Regalón R, Sánchez-Vera I, López-Melgar B, García-Durango C, Castellano Vázquez JM, Solís J, Fernández-Friera L, Vidal-Vanaclocha F. Soluble ICAM 1 and VCAM 1 Blood Levels Alert on Subclinical Atherosclerosis in Non Smokers with Asymptomatic Metabolic Syndrome. Arch Med Res. 2019 Feb;50(2):20-28. doi: 10.1016/j.arcmed.2019.05.003.

18. Pavicic Ivelja M, Ivic I, Dolic K, Mestrovic A, Perkovic N, Jankovic S. Evaluation of cerebrovascular reactivity in chronic hepatitis $\mathrm{C}$ patients using transcranial color 
Doppler. PLoS One. 2019;14(6):e0218206. Published 2019 Jun 11.

19. Apruzzese A, Silvestrini M, Floris R, Vernieri F, Bozzao A, Hagberg G, Caltagirone C, Masala S, Simonetti G. Cerebral hemodynamics in asymptomatic patients with internal carotid artery occlusion: a dynamic susceptibility contrast MR and transcranial Doppler study. AJNR Am J Neuroradiol. 2001 Jun-Jul;22(6):1062-7.

20. Markus HS, Harrison MJG. Estimation of cerebrovascular reactivity using transcranial Doppler, including the use of breath-holding as the vasodilatory stimulus. Stroke 1992;23: 668-673.

21. Silvestrini M, Troisi E, Matteis M, Cupini LM, Caltagirone C. Transcranial Doppler assessment of cerebrovascular reactivity in symptomatic and asymptomatic severe carotid stenosis. Stroke 1996;27:1970-1973.

22. Rimm EB, Klatsky A, Grobbee D, Stampfer MJ. Review of moderate alcohol consumption and reduced risk of coronary heart disease: is the effect due to beer, wine, or spirits. BMJ 1996; 312:731-736.

23. Mukamal KJ, Chen CM, Rao SR, Breslow RA. Alcohol consumption and cardiovascular mortality among U.S. adults, 1987 to 2002. J Am Coll Cardiol 2010 Mar 30;55(13):132835.

24. Stoutenberg M, Lee DC, Sui X, Hooker S, Horigian V, Perrino T, Blair S. Prospective study of alcohol consumption and the incidence of the metabolic syndrome in US men. Br J Nutr 2013 Sep 14;110(5): 901-10. 
291

292

293

294

295

296

297

298

299

300

301

302

303

304

305

306

307

308

309

310

311

312

25. Settakis G, Lengyel A, Molnar C, Bereczki D, Csiba L, Fülesdi B. Transcranial Doppler study of cerebral hemodynamics changes during breath-holding and hyperventilation test. J Neuroimaging 2002;12:252-258.

26. Rodriguez-Flores M, Garcia-Garcia E, Cano-Nigenda CV, Cantu-Brito C. Relationship of obesity and insulin resistance with the cerebrovascular reactivity: a case control study. Cardiovascular Diabetology 2014; 13:2

27. Rosenfeld ME, Campbell LA. Pathogens and atherosclerosis: update on the potential contribution of multiple infectious organisms to the pathogenesis of atherosclerosis. Thromb Haemost 2011 Nov; 106(5):858-67. https://doi.org/10.1160/TH11-06-0392 PMID: 22012133

28. Masiá M, Padilla S, Robledano C, Ramos JM, Gutiérrez F. Evaluation of endothelial function and subclinical atherosclerosis in association with hepatitis C virus in HIVinfected patients: a cross-sectional study. BMC Infect Dis. 2011 Oct 3;11:265. doi: 10.1186/1471-2334-11-265. PMID: 21967471; PMCID: PMC3198698.

29. Campbell LA, Rosenfeld ME. Infection and Atherosclerosis Development. Arch Med Res. 2015;46(5):339-350. doi:10.1016/j.arcmed.2015.05.006

30. Martinic-Popovic I, Simundic AM, Dukic L, Lovrencic-Huzjan A, Popovic A, Seric V, BasicKes V, Demarin V. The association of inflammatory markers with cerebral vasoreactivity and carotid atherosclerosis in transient ischaemic attack. Clin Biochem. 2014 Nov;47(1617):182-6. doi: 10.1016/j.clinbiochem.2014.07.010. Epub 2014 Jul 18.

31. Schmidt FP, Zimmermann T, Wenz T, Schnorbus B, Ostad MA, Feist C, Grambihler A, Schattenberg JM, Sprinzl MF, Münzel T, Galle PR. Interferon- and ribavirin-free therapy 
with new direct acting antivirals (DAA) for chronic hepatitis $C$ improves vascular endothelial function. Int J Cardiol. 2018 Nov 15;271:296-300. doi: 10.1016/j.ijcard.2018.04.058. Epub 2018 Aug 1. Durán R, Gato S, Montero-Vallejo R, Rico MC, Maya-Miles D, Sánchez-Torrijos Y, Soria IC, Stiefel P, Romero-Gómez M. Hepatitis C Virus Clearance by Direct-Acting Antivirals Agents Improves Endothelial Dysfunction and Subclinical Atherosclerosis: HEPCAR Study. Clin Transl Gastroenterol. 2020 Aug;11(8):e00203. doi: 10.14309/ctg.0000000000000203. PMID: 32955194; PMCID: PMC7431267.

33. Davis JS, Young M, Lennox S, Jones T, Piera K, Pickles R, Oakley S. The effect of curing hepatitis $\mathrm{C}$ with direct-acting antiviral treatment on endothelial function. Antivir Ther. 2018;23(8):687-694. doi: 10.3851/IMP3257. PMID: 30048244.

34. Shoamanesh A, Preis SR, Beiser AS, Kase CS, Wolf PA, Vasan RS, Benjamin EJ, Seshadri S, Romero JR. Circulating biomarkers and incident ischemic stroke in the Framingham Offspring Study. Neurology. 2016;87(12):1206-1211. doi:10.1212/WNL.0000000000003115

35. Salum GM, Bader El Din NG, Ibrahim MK, Anany MA, Dawood RM, Khairy A, El Awady MK. Vascular endothelial frowth factor expression in Hepatitis C virus-induced liver fibrosis: a potential biomarker. J Interferon Cytokine Res. 2017 Jul;37(7):310-316. doi: 10.1089/jir.2016.0127. Epub 2017 May 4.

36. Kaplanski G, Farnarier C, Payan MJ, Bongrand P, Durand JM. Increased levels of soluble adhesion molecules in the serum of patients with hepatitis C. Correlation with cytokine 
concentrations and liver inflammation and fibrosis. Dig Dis Sci. 1997 Nov;42(11):2277-

84.

37. Montalto G, Giannitrapani L, Soresi M, Virruso L, Martino DD, Gambino R, Carroccio A, Cervello M. Circulating E-selectin levels in chronic hepatitis C patients with normal or elevated transaminase before and after alpha-interferon treatment. Inflammation. 2001 Apr;25(2):101-8.

38. Staszewski J, Skrobowska E, Piusińska-Macoch R, Brodacki B, Stępień A. Cerebral and Extracerebral Vasoreactivity in Patients With Different Clinical Manifestations of Cerebral Small-Vessel Disease: Data From the Significance of Hemodynamic and Hemostatic Factors in the Course of Different Manifestations of Cerebral Small-Vessel Disease Study. J Ultrasound Med. 2019 Apr;38(4):975-987. doi: 10.1002/jum.14782. Epub 2018 Sep 12. PMID: 30208231. 
Figure 1

Scatter plot of ICAM-1 vs BHI, by control group 
Fig 1. Scatter plot of ICAM-1 vs BHI, by control group

A

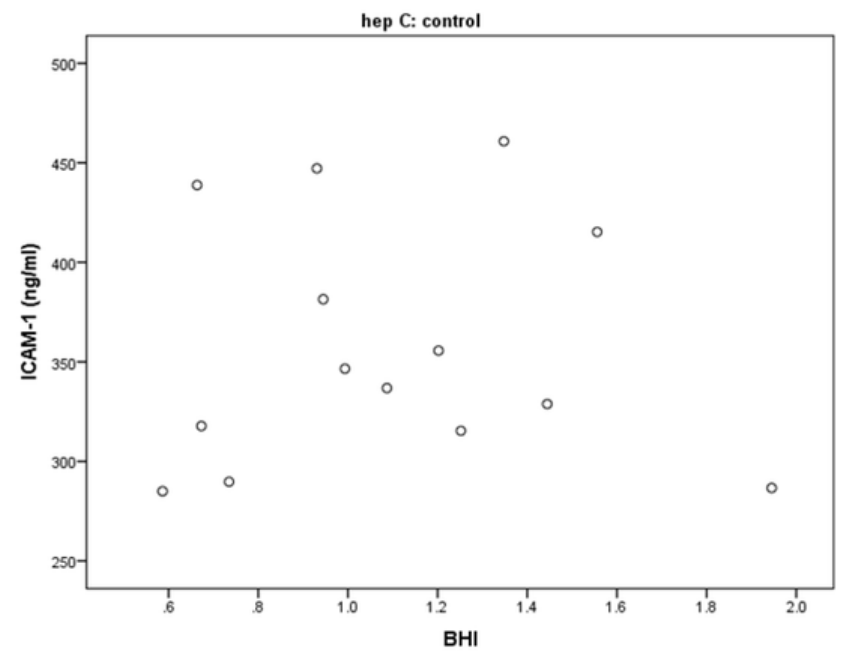

B

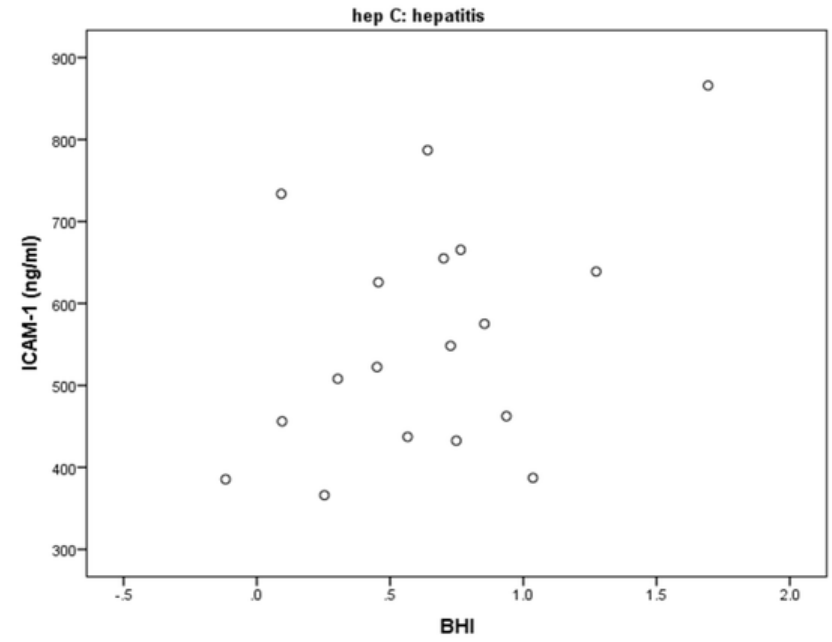




\section{Table $\mathbf{1}$ (on next page)}

Sociodemographic and behavioral characteristics of participants by group

*Independent samples t-test, ** independent Mann-Whitney U test, †Fisher exact test, ^ per week more than 7 drinks for women and 14 drinks for men, ${ }^{\S}$ sex 0 -female, 1 -male; 
1 Table 1. Sociodemographic and behavioral characteristics of participants by group

2

\begin{tabular}{|c|c|c|c|}
\hline & $\begin{array}{l}\text { Control } \\
(\mathrm{N}=18)\end{array}$ & $\begin{array}{l}\text { Hepatitis } \\
(\mathrm{N}=18)\end{array}$ & P-value \\
\hline Age, mean $\pm S D$ & $35,3 \pm 6,5$ & $38,4 \pm 4,8$ & $0.111^{*}$ \\
\hline BMI, median (IQR) & $25,9(4,8)$ & $25,8(5,3)$ & $0.226 * *$ \\
\hline \multicolumn{4}{|l|}{ Sex, N (\%) } \\
\hline $\operatorname{Sex} 0^{\S}$ & $1(6 \%)$ & $3(17 \%)$ & $0.603+$ \\
\hline Sex 1 & 17 (94\%) & $15(83 \%)$ & \\
\hline \multicolumn{4}{|l|}{ Smoking, N (\%) } \\
\hline No & $13(72 \%)$ & $4(22 \%)$ & $0.007+$ \\
\hline Yes & $5(28 \%)$ & $14(78 \%)$ & \\
\hline \multicolumn{4}{|l|}{ Alcohol } \\
\hline No & $10(56 \%)$ & $15(83 \%)$ & $0.146+$ \\
\hline Yes & $8(44 \%)$ & $3(17 \%)$ & \\
\hline
\end{tabular}

4 Legend:

5 *Independent samples t-test, ** independent Mann-Whitney $U$ test, †Fisher exact test, \& per week

6 more than 7 drinks for women and 14 drinks for men, ${ }^{\S}$ sex 0 -female, 1-male;

7

8 


\section{Table 2 (on next page)}

Endothelial markers and BHI distributions by study group

Independent samples t-test, $* *$ independent Mann-Whitney $\mathrm{U}$ test 
1 Table 2. Endothelial markers and BHI distributions by study group

\begin{tabular}{|c|c|c|c|c|}
\hline & Control & Hepatitis & P-value & Mean/median difference \\
\hline $\begin{array}{l}\text { VEGF-A }[\mathrm{pg} / \mathrm{ml}] \\
\text { mean } \pm S D\end{array}$ & $928.07 \pm 390.03$ & $619.71 \pm 260.33$ & $0.009 *$ & $308.4(95 \% \mathrm{Cl} 83.7,533)$ \\
\hline $\begin{array}{l}\text { ICAM-1 [ng/ml]. } \\
\text { median (IQR) }\end{array}$ & $351.10(132.86)$ & $535.40(221.49)$ & $<0.001^{* *}$ & $-167.9(95 \% \mathrm{Cl}-261.7,-89.3)$ \\
\hline $\begin{array}{l}\text { sVCAM-1 [ng/ml]. } \\
\text { median (IQR) }\end{array}$ & $804.66(245.42)$ & $1026.73(647.25)$ & $0.002 * *$ & $-257.6(95 \% \mathrm{Cl}-497.2,-116.4)$ \\
\hline $\begin{array}{l}\text { E-selectin }[\mathrm{ng} / \mathrm{ml}] \text {. } \\
\text { mean } \pm S D\end{array}$ & $69.11 \pm 23.30$ & $85.36 \pm 39.56$ & $0.145^{*}$ & $-16.3(95 \% \mathrm{Cl}-38.4,5.9)$ \\
\hline $\mathrm{BHI}$, mean $\pm \mathrm{SD}$ & $1,10 \pm 0,39$ & $0,64 \pm 0,44$ & $0.005^{*}$ & $0.5(95 \% \mathrm{Cl} 0.2,0.8)$ \\
\hline
\end{tabular}


Table 3 (on next page)

Endothelial marker level differences adjusted for smoking 
1 Table 3. Endothelial marker level differences adjusted for smoking

\begin{tabular}{|c|c|c|c|c|}
\hline & \multirow[t]{2}{*}{ Unstandardized Coefficients B } & \multicolumn{2}{|c|}{$95,0 \%$ Confidence Interval for B } & \multirow{2}{*}{$\begin{array}{c}\mathrm{P} \text { - } \\
\text { value }\end{array}$} \\
\hline & & Lower Bound & Upper Bound & \\
\hline \multicolumn{5}{|c|}{ VEGF-A (pg/ml) } \\
\hline smoking & 19.102 & -244.920 & 283.125 & 0.884 \\
\hline hepatitis C & -317.913 & -581.528 & -54.298 & 0.020 \\
\hline \multicolumn{5}{|c|}{ ICAM-1 (ng/ml) } \\
\hline smoking & 25.215 & -65.681 & 116.111 & 0.576 \\
\hline hepatitis C & 169.386 & 78.631 & 260.142 & 0.001 \\
\hline \multicolumn{5}{|c|}{ sVCAM-1 (ng/ml) } \\
\hline smoking & -480.984 & -1.086 .514 & 124.546 & 0.116 \\
\hline hepatitis C & 844.065 & 239.471 & 1.448 .660 & 0.008 \\
\hline \multicolumn{5}{|c|}{ E-selectin (ng/ml) } \\
\hline smoking & 8.202 & -17.493 & 33.897 & 0.521 \\
\hline hepatitis C & 12.151 & -13.505 & 37.807 & 0.342 \\
\hline \multicolumn{5}{|l|}{$\mathrm{BHI}$} \\
\hline smoking & .085 & -.272 & .442 & .629 \\
\hline hepatitis C & -.502 & -.859 & -.145 & .008 \\
\hline & & & & \\
\hline & & & & \\
\hline
\end{tabular}


Table 4 (on next page)

Association of BHI with endothelial marker levels by study group 
1 Table 4. Association of BHI with endothelial marker levels by study group

\begin{tabular}{|c|c|c|c|c|c|c|}
\hline & & & $\begin{array}{l}\text { VEGF-A } \\
(\mathrm{pg} / \mathrm{ml})\end{array}$ & $\begin{array}{l}\text { ICAM-1 } \\
(\mathrm{ng} / \mathrm{ml})\end{array}$ & $\begin{array}{c}\text { sVCAM-1 } \\
(\mathrm{ng} / \mathrm{ml})\end{array}$ & $\begin{array}{c}\text { E- } \\
\text { selectin } \\
\text { (ng/ml) }\end{array}$ \\
\hline \multirow[t]{5}{*}{ Control } & \multicolumn{2}{|c|}{ Pearson Correlation } & -0.043 & 0.005 & -0.054 & 0.070 \\
\hline & \multirow{2}{*}{$\begin{array}{l}\text { 95\% Confidence } \\
\text { Interval }\end{array}$} & Lower & -0.506 & -0.583 & -0.451 & -0.539 \\
\hline & & Upper & 0.488 & 0.619 & 0.391 & 0.567 \\
\hline & \multicolumn{2}{|l|}{ P-value } & 0.884 & 0.986 & 0.856 & 0.813 \\
\hline & \multicolumn{2}{|l|}{$\mathrm{N}$} & 14 & 14 & 14 & 14 \\
\hline \multirow[t]{5}{*}{ Hepatitis } & \multicolumn{2}{|c|}{ Pearson Correlation } & 0.085 & 0.430 & 0.103 & 0.284 \\
\hline & \multirow{2}{*}{$\begin{array}{l}\text { 95\% Confidence } \\
\text { Interval }\end{array}$} & Lower & -0.254 & -0.262 & -0.194 & -0.342 \\
\hline & & Upper & 0.429 & 0.799 & 0.619 & 0.705 \\
\hline & \multicolumn{2}{|l|}{ Sig. (2-tailed) } & 0.737 & 0.075 & 0.684 & 0.254 \\
\hline & \multicolumn{2}{|l|}{$\mathrm{N}$} & 18 & 18 & 18 & 18 \\
\hline
\end{tabular}

2 